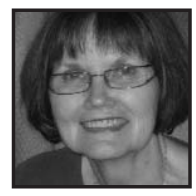

\title{
Commentary:
}

\section{Thoughts on Three Decades in Literacy Education: Why Don't We Ever Learn?}

\author{
Susan Church, Mount Saint Vincent University
}

\section{ABSTRACT}

Literacy teaching and learning and education more generally seem destined to be buffeted by periodic pendulum swings between more and less regulation of curriculum, assessment and teachers' work. Reflecting from a position of seniority, I speculate in this commentary on how the trajectory of progressive and generative theories and practices in literacy education might have been altered if such swings had not been so pervasive over the past several decades. Drawing on insights that have guided my own thirty-plus years of work to advance critically reflective and progressive literacy education, I suggest that greater attention to some wise words from past decades might help today's educators to resist the never-ending pull of the pendulum.

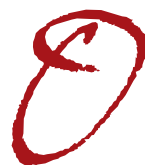

ne of the pleasures of retiring from full-time employment is having the opportunity to teach again after devoting the last two decades of my career to a variety of district-level leadership positions. As a part-time university faculty member, I interact both with teachers and with people aspiring to be teachers. Inevitably, we share stories about our lives and work. When I describe experiences from the 1970s and 1980s, I know that my students view that era as I do the Depression or World War II, as history. I try very hard not to come across like some of the seasoned teachers I remember from early in my career-the ones for whom nothing was new; they had seen it all.Yet, when I encounter young teachers who are struggling to move from teacher-centred classrooms to ones in which children are active participants in reading/writing workshops, I realize that I have been around long 
enough now to have experienced a few swings of that proverbial pendulum-the one that takes us back and forth between greater and lesser external regulation of schooling every fifteen or twenty years.

I was quite a young teacher in 1979 when I joined a group of innovative educators who were replacing their basal readers with children's literature and learning to teach writing as process. Over time, efforts to construct collaborative and holistic approaches to literacy education acquired the label, "whole language." This was not the first time that progressive ideas had caught the attention of researchers and educators-John Dewey's (1938) experiential learning of the 1930s comes to mind. Open and generative forms of pedagogy have a history of waxing and then waning as changing political contexts eventually bring more restrictive practices into dominance. In the case of whole language, the critiques of the perceived lack of attention to language skills such as phonics, spelling and usage ignited heated language wars over whether "meaning first" or "code first" pedagogies should prevail.

I was among those who expressed concerns that the rapid implementation of whole language curricula left many teachers with superficial understandings and many misconceptions about how to support children's growth as language users (Church, 1992, 1994, 1996; Newman \& Church, 1990). What was needed, I argued, was greater attention to the learning needs of teachers, in particular expanding knowledge of the beliefs underlying new practices. Instead, the rhetoric of literacy crisis grew and there were reactive moves: greater specificity in curricular expectations; the re-introduction of commercially published literacy programs; scripted teachers' manuals; and increased reliance on external assessments to determine the success of students, teachers and schools. I am aware that there was significant variation across constituencies in regard to how far the pendulum swung in either direction. For example, in Canada the proliferation of standardized tests has been much less extreme than in the United States, and most provincial curriculum frameworks provide more room to maneuver than is possible in many other contexts. Yet, it is evident that the standardization of curriculum and the imposition of external accountability frameworks became the dominant trend in public education in the 1990s.

There are signs that a swing back is occurring. Recently I came across the following headline, from an article in the Guardian newspaper in the UK (Westland, 2009): "'We want the wow factor.' It is possible for schools to shake off the constraints of the curriculum and be creative." The article went on to describe how teachers in a school in southwest London are working with themes, creating integrated curriculum around large inquiry questions, and to explain how the national primary curriculum is being 
revamped to "allow more flexibility and encourage cross-curricular teaching." Wow, indeed, I thought when I read about the teachers' commitment and the children's excitement over this new-to-them way of teaching and learning. The article could just as well have been written about classrooms in Nova Scotia in the early 1980s.

In some respects, the Guardian article felt like a breath of fresh air as it reconstituted the discourses of the promising early days of whole language: thematic teaching, creativity, flexibility, teacher empowerment, learning by doing, child-friendliness, and student engagement. The practices described in the article provide a hopeful counter-narrative to today's continuing obsession with controlling every aspect of teachers' work and students' learning through externally mandated directives, policies, and tests. I am sure that the critics from the other side are already formulating their arguments for why this move toward greater creativity will undermine the progress that has been made in systematizing curriculum and instruction over the past two decades. No doubt the polarizing debate will continue.

Notwithstanding the positive possibilities represented by the news article, I am troubled that a new generation of teachers seems to be going over the same ground that we traversed two decades ago. Certainly, exploring themes such as castles, aliens, space, and water, as they are in the school in south-west London, is a whole lot better than doing worksheets. Similarly, I am encouraged when teachers in my graduate courses want to move away from writing prompts and whole class texts to enact practices such as reading/writing workshops that I implemented as a teacher in the 1980s. Yet, I also experience a pervasive sense of déjà vu that is disturbing, rather than nostalgic.

When I work with teachers who appear to be taking the same tentative steps I took years ago, I have no choice but to extend their learning from where they are, rather than from where I would like them to be. I find myself negotiating the complexities of both responding to their concerns about how best to engage their students more actively through such practices as reading/writing workshops and extending their awareness of social-constructivist, critical theories of literacy teaching. These current conceptions of literacy problematize the practices of the 1980s as insufficiently reflective of difference and of the multiple ways in which people use language to exercise power across diverse social contexts. Further, toward the end of the first decade of the $21^{\text {st }}$ century, how can I fail to focus on the transformative impact of new literacies? I wonder how our conversations about the complexities of responding to today's generation of literacy learners might be enriched and deepened if I did not have to counter the effects of the reforms of the 1990s. 
As shifting political tides brought pendulum swings within the institutional context in which I worked as a teacher and administrator, I was fortunate to have ongoing access to and engagement with the academic community throughout my career in public education. Those connections supported a gradual and continual evolution of my theoretical and practical understandings of literacy education. In contrast to the experiences of most teachers in the school system-where change typically occurs through settling on a new right answer, often directly contradictory to the previous right answer-in an academic context there were opportunities for open and dynamic consideration of multiple perspectives and a broad range of research. Universities, to the extent that they depend upon governments for funding, are also impacted by changing political contexts. Nonetheless, a full spectrum of theoretical perspectives continues to be represented within academia. Indeed, the contention among those diverse views constitutes the life blood of scholarly journals and conferences.

Over the years as a district level administrator-curriculum supervisor, assistant superintendent, areas superintendent-I was from time to time responsible for implementing a new mandate that represented a pendulum swing. Many teachers probably viewed me as one of the unspecified "they" who periodically drive the school system into a 180-degree turn. Toward the end of my career in public education I completed doctoral research (Church, 2003) in which I constructed a critical analysis of educational leadership and reform, documenting my efforts to negotiate the tensions between institutional role expectations and my beliefs. As I interact with my undergraduate and graduate students, I certainly draw upon the insights that I gained through that investigation. I also, however, reach further into the past to bring to their attention some powerful words that I have carried with me through all of my experiences as a teacher, learner and leader. Three eloquent writers provided similar counsel on how to move beyond the pendulum swings that seem to keep public education in thrall, countering the belief in right answers that underlies these periodic shifts.

More than thirty years ago, in the context of offering insights about the learning and teaching of writing, Peter Elbow (1973) observed, "You're always right and you're always wrong" (p. 106). He advised writers to be aware that, although they may be in charge of their writing, they need to be open to readers' interpretations and feedback and "shed their blinders." I have extrapolated this advice to apply more generally to teaching, educational change and life: a lot of learning can occur if we set aside our truths, our right answers, and, as Elbow suggests, remain simultaneously sure of ourselves and humble. 
Along the same lines, Donald Graves (1984), one of the fathers of the writing process movement of the 1970 s and 80 s, reflected on its trajectory and warned that "the enemy is orthodoxy." These orthodoxies, he argued, were "substitutes for thinking" (p. 185). He went on to list aspects of teaching writing that were becoming inviolate right answers, for example, all pieces should be revised and published, children should always choose their own topics or language conventions are unimportant. At the conclusion, Graves noted, "Orthodoxies make us tell old stories about children at the expense of the new stories that children are telling us today" (p. 193). In my experience, orthodoxies also lead to backlashes because teachers are implementing practices by rote rather than through thinking that leads to deeper understandings. Backlashes, in turn, result in institutional pendulum swings, as systems react and retrench.

Finally, Margaret Meek Spencer, cited by Dillon (1984), urged educators to ask "what if it's otherwise?" (p. 680). Disturbed by the ideologically pure camps represented in articles submitted to him when he was the editor of Language Arts, Dillon used Spencer's question to draw attention to the lack of critical questioning in the debates of that era-debates that subsequently evolved into the full-fledged "language wars" that continue today. Asking "what if it's otherwise?" is a means of sustaining inquiry and learning. If public educators stop searching for right answers and, instead, engage in ongoing critical reflection about theories and practices, we are better prepared to withstand the pressures to comply with politically driven pendulum swings. Such reflection fosters contexts in which individuals and groups with diverse perspectives are open to learning from each other, engage in thoughtful dialogue and refrain from adopting rigid, oppositional stances. As a result, there is less room for backlash since teachers are co-creators of changes in theories and practices rather than recipients of externally generated right answers.

As I contemplate the current public education landscape from my position of seniority, I can see that the quest for right answers continues. Take your pick from among teacher merit pay, professional learning communities, balanced literacy and a plethora of other possibilities. Most of the teachers that I meet in my university classes feel overwhelmed by the number of external expectations raining in on them. I do my best to help them to reflect critically on their beliefs and practices and to adopt a similar stance in their day-to-day work. I also offer lessons from the past that seem to be relevant to today's life in schools. I realize, however, that their capacity to learn from these lessons is limited. When historians witness successive generations reproducing the same problems and solutions again and again, they must wonder as I do, "Why don't we ever learn?" So, I continue to invoke the words of my three 
mentors from the past in hopes that they will empower today's generation of teachers to resist the never-ending swing of the pendulum by asking themselves and others, "What if it's otherwise?"

\section{References}

Church, S. M. (1992). Rethinking whole language: The politics of educational change. In P. Shannon (Ed), Becoming Political (pp. 238-249). Portsmouth, NH: Heinemann.

Church, S. M. (1994). Is whole language really warm and fuzzy? The Reading Teacher, 47(5), 362-370.

Church, S. M. (1996). The future of whole language - Reconstruction or self-destruction? Portsmouth, $\mathrm{NH}$ : Heinemann.

Church, S. M. (2003). School district leadership as political work: Negotiating governmentalities of school reform. Unpublished doctoral dissertation, University of South Australia.

Dewey, J. (1938). Experience and education. New York: Macmillan Publishing Company.
Dillon, D. (1984). Dear readers. Language Arts, 61(7), 679-80.

Elbow, P. (1973). Writing without teachers. New York: Oxford University Press.

Graves, D. (1984). The enemy is orthodoxy. In D. $\mathrm{H}$. Graves, A researcher learns to write (pp. 184-193). Portsmouth, NH: Heinemann Educational Books.

Newman, J. M., \& Church, S. M. (1990). The myths of whole language. The Reading Teacher, $44(1), 20-26$.

Westland, N. (2009). 'We want the wow factor.' The Guardian, May 26. Retrieved May 27, 2009, from http://www.guardian.co.uk/ education/2009/may/26/creativity-schools

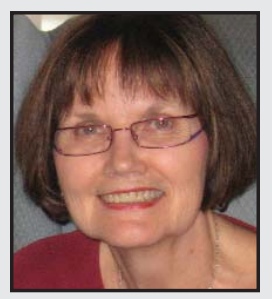

Susan Church is currently a consultant, writer and teacher educator with expertise in literacy teaching/learning, educational leadership, organizational change and gender issues in education. Her doctoral work through the University of South Australia explored the possibilities for educational leadership as political work. She is a part-time faculty member at Mount Saint Vincent University, Halifax, NS, Canada, where she teaches graduate and undergraduate courses in literacy education. She has published widely in educational journals and is the author of several books focused on literacy, educational leadership and inquiry learning. Her most recent book, coauthored with Margaret Swain, From Literature Circles to Blogs: Activities for Professional Learning Communities (Pembroke), was published in September 2009. 